\title{
Microstructure Formation in Cast TiZrHfCoNiCu and CoNiCuAlGaIn High Entropy Shape Memory Alloys: A Comparison
}

\author{
Tetiana A. Kosorukova ${ }^{1}$, Gregory Gerstein ${ }^{2}$, Valerii V. Odnosum ${ }^{1}$, Yuri N. Koval ${ }^{1}$, \\ Hans Jürgen Maier ${ }^{2}$ and Georgiy S. Firstov ${ }^{1, *}$ \\ 1 G.V. Kurdyumov Institute for Metal Physics of the National Academy of Sciences of Ukraine, 36 Vernadsky \\ blvd., 03680 Kiev, Ukraine; tatiana.kosorukova@gmail.com (T.A.K.); odnosum@imp.kiev.ua (V.V.O.); \\ koval@imp.kiev.ua (Y.N.K.) \\ 2 Institut für Werkstoffkunde (Materials Science) Leibniz Universität Hannover, An der Universität 2, \\ 30823 Garbsen, Germany; gerstein@iw.uni-hannover.de (G.G.); maier@iw.uni-hannover.de (H.J.M.) \\ * Correspondence: yuri.firstov@gmail.com; Tel.: +38-044-424-3305
}

Received: 6 November 2019; Accepted: 13 December 2019; Published: 16 December 2019

\begin{abstract}
The present study is dedicated to the microstructure characterization of the as-cast high entropy intermetallics that undergo a martensitic transformation, which is associated with the shape memory effect. It is shown that the TiZrHfCoNiCu system exhibits strong dendritic liquation, which leads to the formation of martensite crystals inside the dendrites. In contrast, in the CoNiCuAlGaIn system the dendritic liquation allows the martensite crystals to form only in interdendritic regions. This phenomenon together with the peculiarities of chemical inhomogeneities formed upon crystallization of this novel multicomponent shape memory alloys systems will be analyzed and discussed.
\end{abstract}

Keywords: dendritic liquation; martensitic transformation; high entropy shape memory alloys

\section{Introduction}

The development of the so-called high entropy alloys (HEA) has triggered a substantial amount of materials research. It all started in 2004 with the concept explained in a publication by J.W. Yeh et al. [1], which has triggered a real breakthrough in the development of structural materials. This concept involves the creation of the multi-element metallic materials close to an equimolar composition, i.e., without a principal element. The entropy of mixing is higher compared to conventional materials and ensures a high phase stability [2-6]. At the same time, the development of the shape memory alloys experienced certain difficulties associated with functional degradation, especially when their envisaged application targeted elevated temperatures [7-11]. HEA are known for their non-obvious solution hardening $[12,13]$. Thus, it has been suggested that the application of the high entropy concept to shape memory alloys might help to overcome the difficulties mentioned above through the suppression of irreversible fatigue effects. The first successful attempt was made using the TiZrHfCuNiCo system. The design employed the B2 TiNi intermetallic compound as a prototype. Exclusion of $\mathrm{Co}$ from the equiatomic composition resulted in a martensitic transformation accompanied by perfect shape memory effect at elevated temperatures due to the significant two-fold increase in strength compared with binary TiNi [14]. It was shown that HEA properties were those that high temperature shape memory alloys needed for their improvement, and a number of six component high entropy shape memory alloys (HESMA) from the TiZrHfCoNiCu system were developed with enhanced yield strength of $1200 \mathrm{MPa}$ and reversible strains up to $2 \%$ in the as-cast state [15]. The peculiar high temperature crystal structure-a triclinically distorted one of the B2 type that carries these distortions into the B19' martensite phase (modeled with the help of ab-initio calculations and 
confirmed by X-ray diffraction measurements) [16]—-was proposed to be the origin of the HESMA yield strength and shape memory behavior enhancement. In this context, it was shown that for the TiZrHfCoNiCu system a B2↔B19' type of martensite transformation takes place [14-16]. Recently, an extra six component system CoNiCuAlGaIn, which emulates the $\mathrm{B} 2 \mathrm{NiAl}$ intermetallic compound was introduced [17]. In the as-cast state, it shows a B2 high temperature structure distorted similarly to TiZrHfCoNiCu and it also carries triclinic distortions into the tetragonal martensitic phase. TEM and DSC results clearly confirm the $\mathrm{B} 2 \leftrightarrow \mathrm{L} 1_{0}$ type of martensitic transformation [17]. Thus, the formation of multi-component intermetallic compounds with a distorted B2 structure undergoing a martensitic transformation appears as a physical regularity, which is important for subsequent shape memory behavior. It should be noted that very recently Lee et al. [18] managed to produce a solid solution CrMnFeCoNi HESMA that exhibit recovery strains of almost $2 \%$. However, the phase transformation is accompanied by irreversible plastic strains of $1 \%-5.8 \%$. In other words, shape recovery is incomplete, and with an increase of pre-strain from $0.9 \%$ to $7.6 \%$, the shape recovery ratio drops from $89 \%$ to $24 \%$. In fact, at the moment the only HESMA that exhibit complete shape recovery up to $2 \%$ are multi-component intermetallic compounds. One of the remarkable features of these HESMA is that they undergo a martensitic transformation and exhibit shape memory behavior in the as-cast state although this is characterized by strong dendritic liquation. Such chemical inhomogeneity is well known for cast HEA (e.g., [1] (p. 300), [2] (pp. 24-25), [3] (pp. 78-112), [13] (pp. 287-288), [19,20]), but was mainly observed and described for solid solutions. Thus, the present study was dedicated to the description and analysis of the microstructural peculiarities that appear after casting of intermetallic HESMA and how martensite formation is taking place under such conditions.

\section{Materials and Methods}

The $\mathrm{Ti}-\mathrm{Zr}-\mathrm{Hf}-\mathrm{Co}-\mathrm{Ni}-\mathrm{Cu}$ and $\mathrm{Co}-\mathrm{Ni}-\mathrm{Cu}-\mathrm{Al}-\mathrm{Ga}-\mathrm{In}$ alloys used in the present investigation were arc-melted from iodide $\mathrm{Ti}, \mathrm{Zr}$, and $\mathrm{Hf}$, electrolytic $\mathrm{Co}, \mathrm{Ni}$, and $\mathrm{Cu}$ and $\mathrm{Al}, \mathrm{Ga}$, and $\mathrm{In}$ of high purity in a pre-gettered argon. Ingots were turned and re-melted nine times to ensure adequate homogeneity. The weight the ingots was typically $5-10 \mathrm{~g}$. Scanning electron microscopy studies were carried out using a Zeiss SUPRA 55 VP field emitter scanning electron microscope (FE-SEM) with a lateral resolution 1.2 $\mathrm{nm}$. For element analysis an EDX system Quantax (silicon drift detector SDD, Series 5010, Type 1108, $30 \mathrm{~mm}^{2}$, Collimator Zr on Chip, Aperture $3.5 \mathrm{~mm}$ ) from Bruker with an energy resolution of $<125 \mathrm{eV}$ FWHM at $\mathrm{MnK}_{\alpha}$ (Peakshift 5-300 kcps $<5 \mathrm{eV}$, at $60 \mathrm{kcps}$ shaper, throughput $1.0 \mu$ s shaping time, 100 kcps input count rate) was employed. Smoothening of the elemental line scan data obtained in the SEM experiments on Co-Ni-Cu-Al-Ga-In alloy was performed using an FFT filter method ( 9 points window) implemented in the OriginPro 2015 software package. Differential thermal analysis (DTA) was performed on a Setaram LabSys 1600 system, calibrated using the phase transitions and melting temperatures of different pure metals. The measurements were performed at heating/cooling rates of $40 \mathrm{~K} \mathrm{~min}^{-1}$, under a $5 \mathrm{~N}$ purity argon flow. The DTA baseline was subtracted using the PeakFit v. 4.12 software. The accuracy of the measurements for the temperatures of the phase transformations was $\pm 7 \mathrm{~K}$.

\section{Results}

Figure 1a shows a comparison of DTA crystallization curves for TiNi binary and $\mathrm{Ti}_{16.67} \mathrm{Zr}_{16.67} \mathrm{Hf}_{16.67} \mathrm{Co}_{16.67} \mathrm{Ni}_{16.67} \mathrm{Cu}_{16.67}$ multicomponent equiatomic compounds. It can be seen that binary equiatomic TiNi exhibit a single peak of crystallization with a width of $65 \mathrm{~K}$ that starts at $1587 \mathrm{~K}$. The crystallization of the equiatomic $\mathrm{Ti}_{16.67} \mathrm{Zr}_{16.67} \mathrm{Hf}_{16.67} \mathrm{Co}_{16.67} \mathrm{Ni}_{16.67} \mathrm{Cu}_{16.67}$ compound starts at a lower temperature of $1530 \mathrm{~K}$ and the major DTA peak associated with it has a width of about $120 \mathrm{~K}$. Further cooling reveals a small peak around $1200 \mathrm{~K}$. 


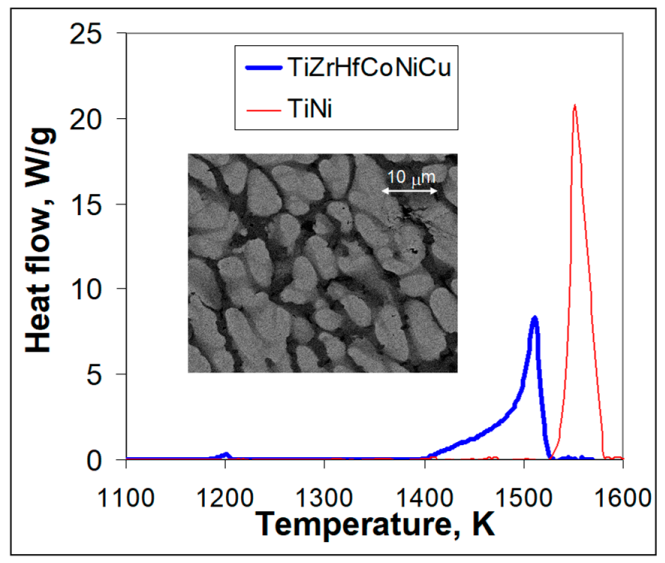

(a)

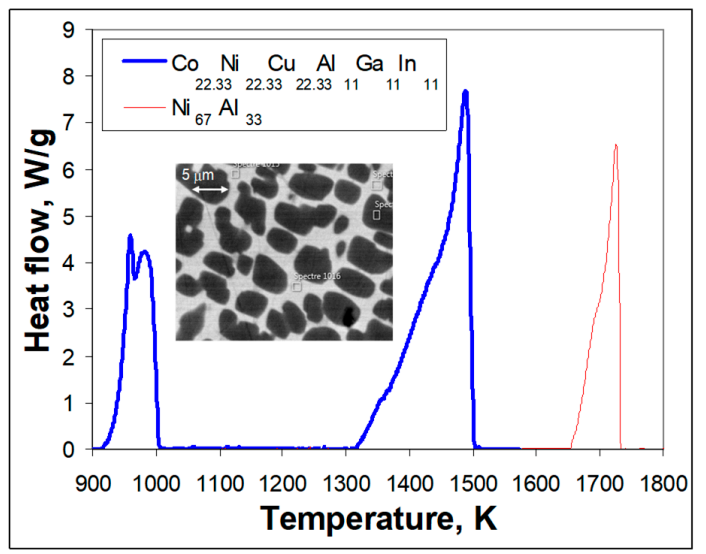

(b)

Figure 1. Heat flow upon crystallization from the liquid (40 K/min cooling rate) and the resulting cast microstructures: (a) red line-equiatomic TiNi and blue one-equiatomic TiZrHfCoNiCu; the inset shows the as-cast TiZrHfCoNiCu microstructure; (b) red line- $\mathrm{Ni}_{67} \mathrm{Al}_{33}$ and blue line- $\mathrm{Co}_{22.33} \mathrm{Ni}_{22.33} \mathrm{Cu}_{22.33} \mathrm{Al}_{11} \mathrm{Ga}_{11} \mathrm{In}_{11}$; the inset shows the as-cast $\mathrm{Co}_{22.33} \mathrm{Ni}_{22.33} \mathrm{Cu}_{22.33} \mathrm{Al}_{11} \mathrm{Ga}_{11} \mathrm{In}_{11}$.

In Figure $1 b$, it can be seen that crystallization of the non-stoichiometric $\mathrm{Ni}_{67} \mathrm{Al}_{33}$ compound shows a two-stage behavior. The primary crystals of the $\mathrm{Ni}_{67} \mathrm{Al}_{33}$ compound begin to precipitate from the liquid phase at a temperature of $1733 \mathrm{~K}$. The appearing crystals are still at equilibria with the liquid until $1687 \mathrm{~K}$. As temperature decreases, the compositions of the crystals and the liquid change and the crystals become enriched in Ni. Finally, at $1687 \mathrm{~K}$ all of the liquid has solidified and there are areas in the as-cast microstructure that are different in composition but all of them belong to the same compound. In the case of crystallization of the $\mathrm{Co}_{22.33} \mathrm{Ni}_{22.33} \mathrm{Cu}_{22.33} \mathrm{Al}_{11} \mathrm{Ga}_{11} \operatorname{In}_{11}$ composition, the major crystallization event starts at $1500 \mathrm{~K}$ and, the crystallization process appears qualitatively similar to the binary $\mathrm{Ni}_{67} \mathrm{Al}_{33}$ compound but the crystallization peak width of $174 \mathrm{~K}$ is more than twice as wide as in the case of $\mathrm{Ni}_{67} \mathrm{Al}_{33}(75 \mathrm{~K})$. Further cooling results in a two-stage event. The first stage starts at $1010 \mathrm{~K}$, while the second one begins around $970 \mathrm{~K}$ (Figure $1 \mathrm{~b}$ ).

It has to be noted that crystallization of the equiatomic $\mathrm{Ti}_{16.67} \mathrm{Zr}_{16.67} \mathrm{Hf}_{16.67} \mathrm{Co}_{16.67} \mathrm{Ni}_{16.67} \mathrm{Cu}_{16.67}$ intermetallic compound takes place with the formation of stable (not undergoing a martensitic transformation) distorted B2 structure based on the X-ray data in [14,16], which show broad reflections. Some of that broadening mostly appears because of the strong dendritic liquation shown in the inset of Figure 1a. Against the background of the dendrites and interdendritic regions small black spots with the composition of $(\mathrm{TiZrHf})_{2}(\mathrm{CoNiCu})$ can be observed in the inset of Figure 1a.

In the case of CoNiCuAlGaIn, the equiatomic split was carried out in the frame of $(\mathrm{CoNiCu})$ and (AlGaIn) groups of atoms $\left(\mathrm{Co}_{22.33} \mathrm{Ni}_{22.33} \mathrm{Cu}_{22.33} \mathrm{Al}_{11} \mathrm{Ga}_{11} \mathrm{In}_{11}\right)$. Crystallization of this composition resulted in the formation of a $\left(\mathrm{Co}_{31.7} \mathrm{Ni}_{26.8} \mathrm{Cu}_{8.5}\right)_{67}\left(\mathrm{Al}_{22.1} \mathrm{Ga}_{10.3} \mathrm{In}_{0.6}\right)_{33}$ phase surrounded preferentially by the $\left(\mathrm{Co}_{6.3} \mathrm{Ni}_{13.5} \mathrm{Cu}_{48.9}\right)_{68.7}\left(\mathrm{Al}_{1.5} \mathrm{Ga}_{4.5} \mathrm{In}_{25.3}\right)_{31.3}$ phase of $\mathrm{Cu}_{9} \mathrm{In}_{4}$ type. These findings are in agreement with the results [17]. In addition, small amounts of the $\left(\mathrm{Co}_{29.7} \mathrm{Ni}_{29.9} \mathrm{Cu}_{14.9}\right)_{73.6}\left(\mathrm{Al}_{9.6} \mathrm{Ga}_{14.7} \mathrm{In}_{1.2}\right)_{26.4}$ phase were observed, which could be distinguished from the previous one by SEM X-ray microanalysis.

It is well known that binary $\mathrm{TiNi}$ and $\mathrm{NiAl}$ intermetallic compounds of the considered stoichiometries exhibit appearance of martensitic microstructures upon cooling to room temperature. However, the equiatomic $\mathrm{Ti}_{16.67} \mathrm{Zr}_{16.67} \mathrm{Hf}_{16.67} \mathrm{Co}_{16.67} \mathrm{Ni}_{16.67} \mathrm{Cu}_{16.67}$ intermetallic compound [14] and the quasi-equiatomic $\left(\mathrm{Co}_{22.33} \mathrm{Ni}_{22.33} \mathrm{Cu}_{22.33} \mathrm{Al}_{11} \mathrm{Ga}_{11} \mathrm{In}_{11}\right)$ (inset in Figure $1 \mathrm{~b}$ ) did not show any sign of martensite. In the case of the TiZrHfCoNiCu system, a variation of the $\mathrm{Co}, \mathrm{Ni}$, and $\mathrm{Cu}$ content was needed to introduce a martensitic transformation associated with shape memory behavior [15]. In particular, the composition $\mathrm{Ti}_{16.67} \mathrm{Zr}_{16.67} \mathrm{Hf}_{16.67} \mathrm{Co}_{10} \mathrm{Ni}_{25} \mathrm{Cu}_{15}$ has shown a martensitic transformation and shape memory at elevated temperatures. This composition was chosen in the present study for further detailed microstructure examination because of the possibility to observe martensite crystal formation against the dendritic liquation background. Similarly, in Reference [17] the general 
composition of $\mathrm{Co}_{31.22} \mathrm{Ni}_{29.26} \mathrm{Cu}_{11.95} \mathrm{Al}_{16.64} \mathrm{Ga}_{10.39} \mathrm{In}_{0.55}$ has demonstrated high temperature martensitic transformation and, as a result, a certain amount of martensite crystals have been formed against the background of a strong dendritic liquation.

Figure 2 shows heat releases upon cooling from the liquid state followed by crystallization for $\mathrm{Ti}_{16.67} \mathrm{Zr}_{16.67} \mathrm{Hf}_{16.67} \mathrm{Co}_{10} \mathrm{Ni}_{25} \mathrm{Cu}_{15}$ (Figure 2a) and $\mathrm{Co}_{31.22} \mathrm{Ni}_{29.26} \mathrm{Cu}_{11.95} \mathrm{Al}_{16.64} \mathrm{Ga}_{10.39} \mathrm{In}_{0.55}$ multicomponent intermetallic compounds (Figure $2 \mathrm{~b}$ ) as compared to equiatomic TiNi (Figure 2a) and non-stoichiometric $\mathrm{Ni}_{67} \mathrm{Al}_{33}$ (Figure $2 \mathrm{~b}$ ), respectively.

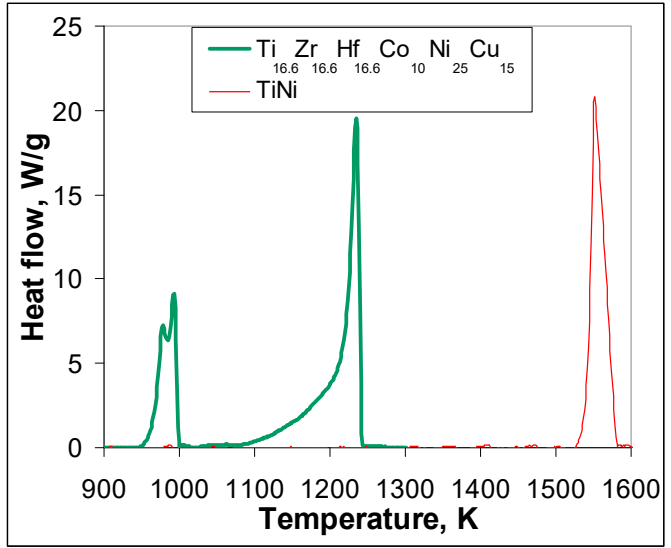

(a)

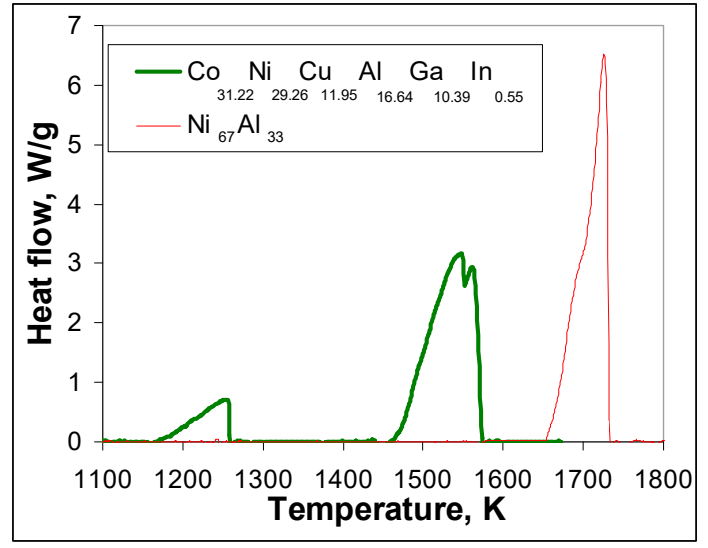

(b)

Figure 2. Heat flow upon crystallization from the liquid and further cooling $(40 \mathrm{~K} / \mathrm{min}$ cooling rate) of binary and multicomponent compounds: (a) red line-equiatomic TiNi and blue one-non-equiatomic $\mathrm{Ti}_{16.67} \mathrm{Zr}_{16.67} \mathrm{Hf}_{16.67} \mathrm{Co}_{10} \mathrm{Ni}_{25} \mathrm{Cu}_{15}$; (b) red line- $\mathrm{Ni}_{67} \mathrm{Al}_{33}$ and blue line- $\mathrm{Co}_{31.22} \mathrm{Ni}_{29.26} \mathrm{Cu}_{11.95} \mathrm{Al}_{16.64} \mathrm{Ga}_{10.39} \mathrm{In}_{0.55}$.

It can be seen (Figure 2a) that the crystallization temperature for the not quite equiatomic composition $\mathrm{Ti}_{16.67} \mathrm{Zr}_{16.67} \mathrm{Hf}_{16.67} \mathrm{Co}_{10} \mathrm{Ni}_{25} \mathrm{Cu}_{15}$ is lower $(1250 \mathrm{~K})$ compared with the equiatomic one (1587 K, Figure 1a). In other words, the decrease in crystallization temperature as compared to binary TiNi is much higher for $\mathrm{Ti}_{16.67} \mathrm{Zr}_{16.67} \mathrm{Hf}_{16.67} \mathrm{Co}_{10} \mathrm{Ni}_{25} \mathrm{Cu}_{15}$ (337 K) than for equiatomic $\mathrm{Ti}_{16.67} \mathrm{Zr}_{16.67} \mathrm{Hf}_{16.67} \mathrm{Co}_{16.67} \mathrm{Ni}_{16.67} \mathrm{Cu}_{16.67}$ (only $57 \mathrm{~K}$ ). The width of the crystallization peak is also 2.5 times larger for the non-equiatomic compound (164 K, Figure 2a) than for TiNi (65 K Figures 1a and $2 \mathrm{a})$, while in the case of the equiatomic one it is just 1.8 times as wide. Further cooling in the already solid state below $1090 \mathrm{~K}$ results in two overlapping peaks starting at $1006 \mathrm{~K}$ and $987 \mathrm{~K}$, which have a width together of about $50 \mathrm{~K}$.

In the case of non-stoichiometric $\mathrm{CO}_{31.22} \mathrm{Ni}_{29.26} \mathrm{Cu}_{11.95} \mathrm{Al}_{16.64} \mathrm{Ga}_{10.39} \mathrm{In}_{0.55}$ deviation from the initial composition resulted not only in the appearance of a martensitic transformation [17] but also in an increase in crystallization temperature from $1500 \mathrm{~K}$ in $\mathrm{Co}_{22.33} \mathrm{Ni}_{22.33} \mathrm{Cu}_{22.33} \mathrm{Al}_{11} \mathrm{Ga}_{11} \mathrm{In}_{11}$ (Figure 1b) to $1580 \mathrm{~K}$ (Figure $2 \mathrm{~b}$ ). In Figure 2b, the width of the peak is more narrow (115 K) than for $\mathrm{Co}_{22.33} \mathrm{Ni}_{22.33} \mathrm{Cu}_{22.33} \mathrm{Al}_{11} \mathrm{Ga}_{11} \mathrm{In}_{11}(174 \mathrm{~K}$, Figure $1 \mathrm{~b})$. Further cooling from $1465 \mathrm{~K}$ revealed one prolonged peak. It starts at $1263 \mathrm{~K}$ (width about $90 \mathrm{~K}$ ).

Figure $3 \mathrm{a}, \mathrm{b}$ show room temperature as-cast microstructures for $\mathrm{Ti}_{16.67} \mathrm{Zr}_{16.67} \mathrm{Hf}_{16.67} \mathrm{Co}_{10} \mathrm{Ni}_{25} \mathrm{Cu}_{15}$ and $\mathrm{Co}_{31.22} \mathrm{Ni}_{29.26} \mathrm{Cu}_{11.95} \mathrm{Al}_{16.64} \mathrm{Ga}_{10.39} \mathrm{In}_{0.55}$ compounds, respectively.

It is obvious that in both cases shown in Figure 3, the formation of the martensite phase takes place against the background of dendritic liquation. The interdendritic regions are decorated by pores and the formation of the phases occurs in an inhomogeneous matrix. Clearly, improved processing could address these issues and help to fully exploit the potential of these alloys. 


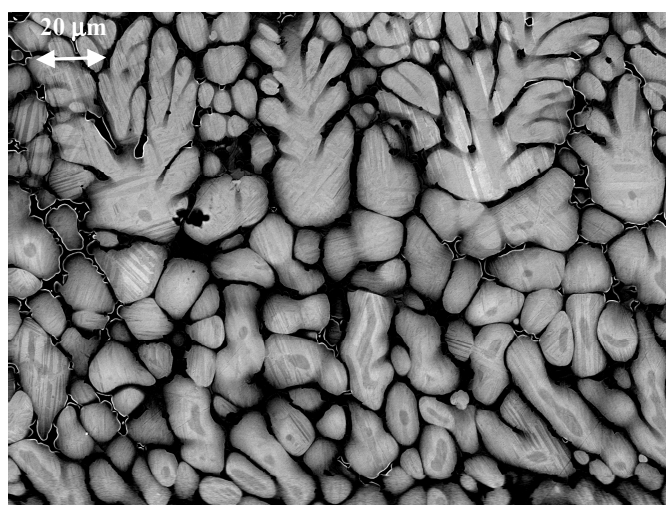

(a)

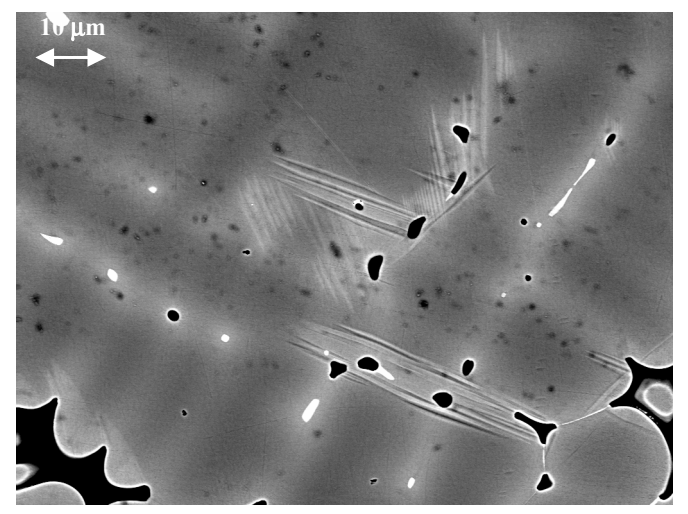

(b)

Figure 3. SEM as-cast microstructures observed using back-scattered electrons contrast: (a) $\mathrm{Ti}_{16.67} \mathrm{Zr}_{16.67} \mathrm{Hf}_{16.67} \mathrm{Co}_{10} \mathrm{Ni}_{25} \mathrm{Cu}_{15}$ and (b) $\mathrm{Co}_{31.22} \mathrm{Ni}_{29.26} \mathrm{Cu}_{11.95} \mathrm{Al}_{16.64} \mathrm{Ga}_{10.39} \mathrm{In}_{0.55}$.

In the case of $\mathrm{Ti}_{16.67} \mathrm{Zr}_{16.67} \mathrm{Hf}_{16.67} \mathrm{Co}_{10} \mathrm{Ni}_{25} \mathrm{Cu}_{15}$, the whole area of dendrites seems to be filled by martensite crystals of mostly plate like morphology (Figure 3a). Some of the interdendritic regions can be distinguished from the dendrites by the rather sharp contrast between them.

Figure $3 b$ represents a different microstructure that forms in $\mathrm{Co}_{31.22} \mathrm{Ni}_{29.26} \mathrm{Cu}_{11.95}$ $\mathrm{Al}_{16.64} \mathrm{Ga}_{10.39} \mathrm{In}_{0.55}$. First, the contrast between dendrites and interdendritic regions is much less, as compared to $\mathrm{Ti}_{16.67} \mathrm{Zr}_{16.67} \mathrm{Hf}_{16.67} \mathrm{Co}_{10} \mathrm{Ni}_{25} \mathrm{Cu}_{15}$ (Figure 3a), and, secondly, martensitic crystals have formed only in interdendritic regions seemingly being stopped from entering the dendrites. In addition, there is a more subtle difference between the microstructures in Figure 3a,b. The dendrites in Figure 3a appear brighter than the interdendritic regions, while in Figure $3 b$ the situation is vice versa. Moreover, the second phase in the interdendritic region in Figure 3a appears black, while in Figure $3 b$ it is white.

The inset in the center of Figure 4 a demonstrates the as-cast $\mathrm{Ti}_{16.67} \mathrm{Zr}_{16.67} \mathrm{Hf}_{16.67} \mathrm{Co}_{10} \mathrm{Ni}_{25} \mathrm{Cu}_{15}$ microstructure. The arrowed line appearing in both insets marks the same position, which was used to record EDX line scan data. The upper part of Figure 4a represents a higher magnification detail of the microstructure alongside the arrowed line that corresponds to the concentration profiles of $\mathrm{Ti}, \mathrm{Zr}$ and Hf obtained from the EDX analysis. Figure $4 \mathrm{~b}$ is structured similarly but represents the data for the $\mathrm{Co}, \mathrm{Ni}$ and $\mathrm{Cu}$ concentration profiles. The line scan goes across two black precipitates, which are several micrometer thick and follows a martensite crystal that starts from one precipitate and stops at the other. Black in the back-scattered electron image corresponds to the area with lowest average atomic number (so-called $\mathrm{Z}$ contrast). From the scan data it was determined that the composition of the black appearing phase is $\left(\mathrm{Ti}_{32} \mathrm{Zr}_{21.5} \mathrm{Hf}_{8.5}\right)_{62}\left(\mathrm{Co}_{4} \mathrm{Ni}_{17} \mathrm{Cu}_{17}\right)_{38}$, which is in accordance with the findings shown in Figure $1 \mathrm{a}$, where the phase of the $\mathrm{Ti}_{2} \mathrm{Ni}$ type was also found. On the right hand side of the scan (positioned at 45-49 $\mu \mathrm{m}$ in Figure 1) there is another area that is brighter and possesses a composition of $\left(\mathrm{Ti}_{21} \mathrm{Zr}_{20} \mathrm{Hf}_{9}\right)_{50}\left(\mathrm{Co}_{5} \mathrm{Ni}_{21} \mathrm{Cu}_{24}\right)_{50}$. The latter is the one that seems to be belonging to the B2 phase as no martensite crystals are seen in it. Yet, both compositions are not the major ones in the scan under consideration. Brighter patches about $10 \mu \mathrm{m}$ long (upper inset in Figure 4) belong to dendrites with the composition $\left(\mathrm{Ti}_{14.7} \mathrm{Zr}_{13.6} \mathrm{Hf}_{19.5}\right)_{47.8}\left(\mathrm{Co}_{13} \mathrm{Ni}_{26.2} \mathrm{Cu}_{13}\right)_{52.2}$ and are filled by martensitic crystals (Figure $4 \mathrm{a}$, central inset). The areas in between them that are few micrometer thick have the composition $\left(\mathrm{Ti}_{19} \mathrm{Zr}_{17.4} \mathrm{Hf}_{12.4}\right)_{48.8}\left(\mathrm{Co}_{7.9} \mathrm{Ni}_{24.4} \mathrm{Cu}_{18.9}\right)_{52.2}$, which is just in between the composition of the dendrites and dark appearing area $\left(\left(\mathrm{Ti}_{21} \mathrm{Zr}_{20} \mathrm{Hf}_{9}\right)_{50}\left(\mathrm{Co}_{5} \mathrm{Ni}_{21} \mathrm{Cu}_{24}\right)_{50}\right)$.

Figure 5 shows SEM results obtained in a similar manner for the as-cast $\mathrm{Co}_{31.22} \mathrm{Ni}_{29.26} \mathrm{Cu}_{11.95}$ $\mathrm{Al}_{16.64} \mathrm{Ga}_{10.39} \mathrm{In}_{0.55}$ microstructure. 


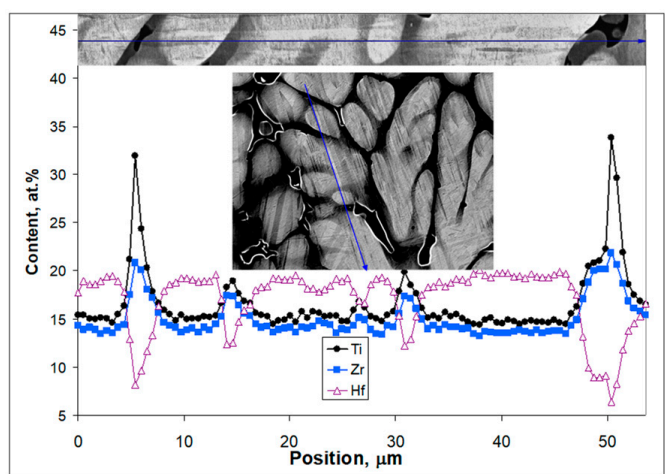

(a)

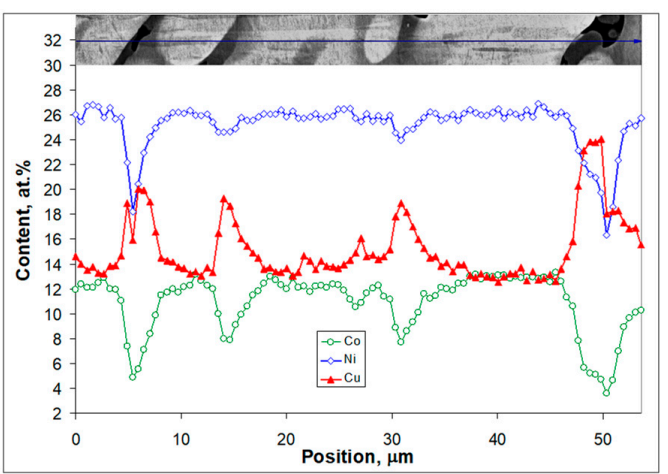

(b)

Figure 4. SEM images using back-scattered electron contrast and corresponding EDX line scan analysis for as-cast $\mathrm{Ti}_{16.67} \mathrm{Zr}_{16.67} \mathrm{Hf}_{16.67} \mathrm{Co}_{10} \mathrm{Ni}_{25} \mathrm{Cu}_{15}$ : (a) Ti (closed circles), $\mathrm{Zr}$ (closed rectangles), Hf (open triangles) concentration profiles along the line shown in the upper inset; the central inset displays an overview of the microstructure along with line that is also shown in the upper inset; (b) Co (opened circles), $\mathrm{Ni}$ (opened rectangles), Hf (closed triangles) concentration profiles along the line shown in the upper inset.

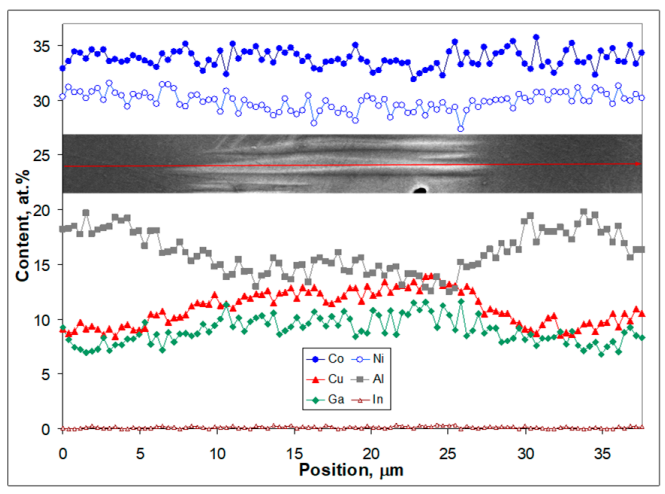

(a)

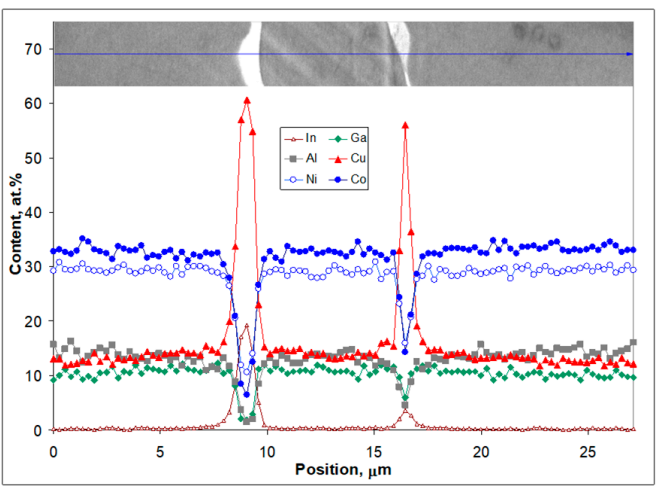

(b)

Figure 5. SEM images along with EDX line scan analysis for as-cast $\mathrm{Co}_{31.22} \mathrm{Ni}_{29.26} \mathrm{Cu}_{11.95}$ $\mathrm{Al}_{16.64} \mathrm{Ga}_{10.39} \mathrm{In}_{0.55}$ : (a) concentration profiles for all elements along the arrowed line recorded along and beyond the individual martensite crystal; (b) concentration profiles for all elements along the arrowed line recorded along the center of the interdendritic region.

It can be seen that the scan line in Figure 5a starts in a dark appearing region belonging to a dendrite and enters a brighter interdendritic region filled with martensite crystals. It passes through an individual $20-\mu \mathrm{m}$ long martensite crystal, which stays within the interdendritic region. At the position where the scan line enters another dark appearing dendrite, the martensite crystal seems to stop from entering it. Other martensite crystals nearby display similar behavior (see also Figure 3b). Figure 5b shows a scan that goes through an interdendritic region. It crosses two bright appearing phases, which according to the data shown in Figure $5 \mathrm{~b}$ have a composition of $\mathrm{Co}_{6.4} \mathrm{Ni}_{10.6} \mathrm{Cu}_{60.7} \mathrm{Al}_{1.4} \mathrm{Ga}_{1.7} \mathrm{In}_{19.2}$. This is close to the one of the $\mathrm{Cu}_{9} \mathrm{In}_{4}$ type found in [17]. The average composition of the dendrites shown in Figure 5a is $\left(\mathrm{Co}_{33.9} \mathrm{Ni}_{30.5} \mathrm{Cu}_{9.4}\right)_{73.8}\left(\mathrm{Al}_{18.2} \mathrm{Ga}_{7.9} \mathrm{In}_{0.1}\right)_{26.2}$. It changes smoothly in Figure $5 \mathrm{a}$, as the scan is moving into the interdendritic area and undergoes a clear decrease in Al content, slight decrease in Co and $\mathrm{Ni}$ and a definite increase in $\mathrm{Cu}$ and $\mathrm{Ga}$. The average composition of the interdendritic region extracted from the data in Figure $5 \mathrm{~b}$ is $\left(\mathrm{Co}_{32.7} \mathrm{Ni}_{29.4} \mathrm{Cu}_{13.3}\right)_{75.4}\left(\mathrm{Al}_{13.8} \mathrm{Ga}_{10.6} \mathrm{In}_{0.2}\right)_{24.6}$.

Apparently, in both cases (TiZrHfCoNiCu and CoNiCuAlGaIn) the martensite crystals appear only in specific regions, which have a composition that best suit their respective stability as compared to the austenite B2 phase. The key difference is that for TiZrHfCoNiCu the martensite forms in dendrites, while for CoNiCuAlGaIn it forms in the interdendritic regions. In the following, the results concerning the crystallization process, formation of chemical inhomogeneities, and further formation 
of martensite crystals against the background of the inhomogeneities observed for the multicomponent TiZrHfCoNiCu and CoNiCuAlGaIn HESMA will be addressed in more detail.

\section{Discussion}

It is clear that the crystallization of multicomponent intermetallic compounds of the TiZrHfCoNiCu and $\mathrm{CoNiCuAlGaIn}$ type is quite different from the crystallization of binary TiNi and $\mathrm{NiAl}$ (Figures 1 and 2). The crystallization temperatures are lower for the multicomponent compounds and the temperature intervals of crystallization are much wider. In the case of equiatomic TiZrHfCoNiCu, nine possible binary equiatomic compositions (corresponding to the compounds $\mathrm{TiCo}, \mathrm{ZrCo}, \mathrm{HfCo}$, $\mathrm{TiNi}$, $\mathrm{ZrNi}, \mathrm{HfNi}, \mathrm{TiCu}, \mathrm{ZrCu}$, and $\mathrm{HfCu}$ ) crystallize together. As a result, the decrease in temperature of their joint solidification and the widening of their mutual crystallization temperature interval are expected. The solidus temperatures for all mentioned binaries were extracted from binary phase diagrams [21] and are summarized in Table 1 along with estimated decreases in crystallization temperature.

Table 1. Solidus temperatures $\left(T_{\mathrm{sol}}\right)$ for binary compounds with different stoichiometries taken from binary phase diagrams [21]; decrease in solidus temperature estimation for nine AB compositions comparing with the composition with the highest solidus (HfCo for systems ${ }^{1}$ and ${ }^{2} \Delta T_{\text {sol }}=\left(T_{\text {HfCo-sol }}\right.$ $\left.-T_{\text {AB-sol }}\right) / 9 ; \mathrm{Co}_{67} \mathrm{Al}$ for ${ }^{3} \Delta T_{\text {sol }}=\left(T_{\text {Co67Al-sol }}-T_{\text {A67B-sol }}\right) / 9$ and $\mathrm{CO}_{73} \mathrm{Al}$ for ${ }^{4} \Delta T_{\text {sol }}=\left(T_{\text {Co73Al-sol }}-\right.$ $\left.T_{\text {A73B-sol }} / 6\right)$ within the multicomponent high entropy compound; crystallization temperatures for multicomponent high entropy compounds calculated as $T_{\text {cryst }}{ }^{1,2}=T_{\mathrm{HfCo}-\mathrm{sol}}-\left(\Sigma \Delta T_{\text {sol }}\right)$ and $T_{\text {cryst }}{ }^{3,4}=$ $T_{\text {CoAl-sol }}-\left(\Sigma \Delta T_{\text {sol }}\right)$.

\begin{tabular}{|c|c|c|c|c|c|c|c|c|c|c|}
\hline & TiCo & ZrCo & HfCo & TiNi & $\mathrm{ZrNi}$ & HfNi & $\mathrm{TiCu}$ & $\mathrm{ZrCu}$ & $\mathrm{HfCu}$ & $T_{\text {cryst }}$ HEA, $\mathrm{K}$ \\
\hline${ }^{1} T_{\text {sol }}, \mathrm{K}$ & 1598 & 1673 & 1913 & 1586 & 1533 & 1803 & 1251 & 1208 & 1253 & \multirow[b]{2}{*}{1535} \\
\hline${ }^{1} \Delta T_{\text {sol }}, K$ & 35 & 26.66 & 0 & 36.33 & 42.22 & 12.22 & 73.55 & 78.33 & 73.33 & \\
\hline${ }^{2} T_{\text {sol, }}, \mathrm{K}$ & 1508 & 1585 & 1823 & 1239 & 1283 & 1466 & 1206 & 1163 & 1243 & \multirow{2}{*}{1264} \\
\hline \multirow[t]{2}{*}{${ }^{2} \Delta T_{\text {sol, }}, \mathrm{K}$} & 52.5 & 39.66 & 0 & 97.33 & 90 & 59.5 & 102.83 & 110 & 96.66 & \\
\hline & $\mathrm{Co}_{67} \mathrm{Al}$ & $\mathrm{Co}_{67} \mathrm{Ga}$ & $\mathrm{Co}_{67} \mathrm{In}$ & $\mathrm{Ni}_{67} \mathrm{Al}$ & $\mathrm{Ni}_{67} \mathrm{Ga}$ & $\mathrm{Ni}_{67} \mathrm{In}$ & $\mathrm{Cu}_{67} \mathrm{Al}$ & $\mathrm{Cu}_{67} \mathrm{Ga}$ & $\mathrm{Cu}_{67} \mathrm{In}$ & $T_{\text {cryst }}$ HEA, $\mathrm{K}$ \\
\hline${ }^{3} T_{\text {sol, }} \mathrm{K}$ & 1849 & 1483 & 1559 & 1778 & 1483 & 1223 & 1311 & 1098 & 938 & \multirow[b]{2}{*}{1485} \\
\hline \multirow[t]{2}{*}{${ }^{3} \Delta T_{\text {sol, }}, K$} & 0 & 40.666 & 32.22 & 7.888 & 40.666 & 69.55 & 59.77 & 83.44 & 101.2 & \\
\hline & $\mathrm{Co}_{73} \mathrm{Al}$ & $\mathrm{Co}_{73} \mathrm{Ga}$ & $\mathrm{Co}_{73} \mathrm{In}$ & $\mathrm{Ni}_{73} \mathrm{Al}$ & $\mathrm{Ni}_{73} \mathrm{Ga}$ & $\mathrm{Ni}_{73} \mathrm{In}$ & $\mathrm{Cu}_{73} \mathrm{Al}$ & $\mathrm{Cu}_{73} \mathrm{Ga}$ & $\mathrm{Cu}_{73} \mathrm{In}$ & $T_{\text {cryst }}$ HEA, $\mathrm{K}$ \\
\hline${ }^{4} T_{\text {sol, }} \mathrm{K}$ & 1773 & 1526 & - & 1668 & 1480 & - & 1318 & 953 & - & \multirow{2}{*}{1593} \\
\hline${ }^{4} \Delta T_{\text {sol, }}, K$ & 0 & 41.166 & - & 17.5 & 48.833 & - & 75.833 & 136.66 & - & \\
\hline
\end{tabular}

It can be seen that HfCo demonstrates the highest solidus temperature. The estimation of the decrease in solidus temperature for each of the nine $\mathrm{AB}$ compositions can be expressed as $\Delta T_{\text {sol }}=\left(T_{\mathrm{HfCo}-\mathrm{sol}}-T_{\mathrm{AB}-\mathrm{sol}}\right) / 9$ and the solidification temperature of the multicomponent composition is obtained by the subtraction of the sum of the individual decreases for each $\mathrm{AB}$ composition from the solidus temperature of HfCo $\left(T_{\text {cryst }}=T_{\mathrm{HfCo}-\mathrm{sol}}-\left(\Sigma \Delta T_{\mathrm{sol}}\right)\right.$. For the exact equiatomic composition $\mathrm{Ti}_{16.67} \mathrm{Zr}_{16.67} \mathrm{Hf}_{16.67} \mathrm{Co}_{16.67} \mathrm{Ni}_{16.67} \mathrm{Cu}_{16.67}$ it is $1535 \mathrm{~K}$ (Table 1), which is almost the same as the experimental value of $1530 \mathrm{~K}$ (Figure 1a). In the case of the $\mathrm{Ti}_{16.67} \mathrm{Zr}_{16.67} \mathrm{Hf}_{16.67} \mathrm{Co}_{10} \mathrm{Ni}_{25} \mathrm{Cu}_{15}$, the solidus temperatures were taken for each binary composition from phase diagrams in [21] taking into account the deficiency in $\mathrm{Co}$ and the excess in $\mathrm{Ni}$ and $\mathrm{Cu}$ as compared with the equiatomic $\mathrm{Ti}_{16.67} \mathrm{Zr}_{16.67} \mathrm{Hf}_{16.67} \mathrm{Co}_{16.67} \mathrm{Ni}_{16.67} \mathrm{Cu}_{16.67}$ composition. The calculated value for the crystallization temperature of $\mathrm{Ti}_{16.67} \mathrm{Zr}_{16.67} \mathrm{Hf}_{16.67} \mathrm{Co}_{10} \mathrm{Ni}_{25} \mathrm{Cu}_{15}$ compound is $1264 \mathrm{~K}$ (Table 1), which is again quite close to the experimental value of $1250 \mathrm{~K}$ (Figure 2a).

The same consideration was applied for the non-stoichiometric CoNiCuAlGaIn multicomponent intermetallic compounds. In this case, amongst the nine possible binary equiatomic compositions (corresponding to compounds $\mathrm{CoAl}, \mathrm{CoGa}, \mathrm{CoIn}, \mathrm{NiAl}, \mathrm{NiGa}$, NiIn, $\mathrm{CuAl}, \mathrm{CuGa}$, and $\mathrm{CuIn}$ ) the highest solidus temperature is demonstrated by the equiatomic $\mathrm{CoAl}\left(T_{\mathrm{CoAl}-\text { sol }}=1913 \mathrm{~K}\right.$ [21]), 
which is, by the way, the same as the one for HfCo. The calculated crystallization temperature for $\mathrm{Co}_{22.33} \mathrm{Ni}_{22.33} \mathrm{Cu}_{22.33} \mathrm{Al}_{11} \mathrm{Ga}_{11} \mathrm{In}_{11}$ is $1485 \mathrm{~K}$ (Table 1) and the experimental value is 1500 $\mathrm{K}$ (Figure $1 \mathrm{~b}$ ), which is not too far off. The change in general stoichiometry from 67:33 in $\left(\mathrm{Co}_{22.33} \mathrm{Ni}_{22.33} \mathrm{Cu}_{22.33}\right)_{67}\left(\mathrm{Al}_{11} \mathrm{Ga}_{11} \mathrm{In}_{11}\right)_{33}$ to $73: 27$ in $\left(\mathrm{Co}_{31.22} \mathrm{Ni}_{29.26} \mathrm{Cu}_{11.95}\right)_{73}\left(\mathrm{Al}_{16.64} \mathrm{Ga}_{10.39} \mathrm{In}_{0.55}\right)_{27}$ is also accompanied by a drastic decrease in In content to the point where the binary composition can be taken out from the consideration (Table 1). The calculated value for the crystallization temperature of $\left(\mathrm{Co}_{31.22} \mathrm{Ni}_{29.26} \mathrm{Cu}_{11.95}\right)_{73}\left(\mathrm{Al}_{16.64} \mathrm{Ga}_{10.39} \mathrm{In}_{0.55}\right)_{27}$ is $1593 \mathrm{~K}$ (Table 1), which is close to the experimental value of $1580 \mathrm{~K}$ (Figure $2 \mathrm{~b}$ ).

In both cases described above that demonstrated such a good fit of experimental and calculated values of crystallization temperatures, the HfCo and CoAl intermetallic compounds (being the most refractory ones) were considered as the major constituents with respect to crystallization, while other binaries were assumed to just follow during the crystallization process. It also means that the final microstructures should have dendrites with excess of $\mathrm{HfCo}$ or $\mathrm{CoAl}$ in their composition, as compared to the interdendritic regions, which should be enriched in lower melting point constituents.

It should be noted that the DTA results (Figures 1 and 2) show additional exothermal peaks upon further cooling following the crystallization process. These are indications of certain phase transformations that add up to the formation of the final microstructures. Generally, this means that the stabilizing effect of the higher entropy of mixing decreases with decreasing temperature and at certain point precipitation of second phases follows. To consider this situation more properly, one needs to have an idea about the contribution of enthalpy and entropy of mixing. Both values for all multicomponent intermetallics considered have been summarized in Table 2.

Table 2. Enthalpies of mixing $\left(\Delta H_{\text {mix }}\right)$ calculated in [22] by Miedema's model for atomic pairs and calculated in the present study for TiZrHfCoNiCu ( ${ }^{1}$ and ${ }^{2}$ compositions) and CoNiCuAlGaIn ( ${ }^{3}$ and ${ }^{4}$ compositions) according to [23]; corresponding entropies of mixing a provided in the footnote.

\begin{tabular}{|c|c|c|c|c|c|c|c|c|c|c|c|c|c|c|c|}
\hline & TiCo & ZrCo & HfCo & TiNi & $\mathrm{ZrNi}$ & HfNi & $\mathrm{TiCu}$ & $\mathrm{ZrCu}$ & $\mathrm{HfCu}$ & $\mathrm{NiCu}$ & $\mathrm{CoCu}$ & & & & HEA \\
\hline $\begin{array}{l}\Delta H_{\text {mix }} \\
\mathrm{kJ} / \mathrm{mol}\end{array}$ & -28 & -41 & -35 & -35 & -49 & -42 & -9 & -23 & -17 & 4 & 6 & & & & $\begin{array}{l}1-29.9 \\
2-31.9\end{array}$ \\
\hline & CoAl & CoGa & CoIn & NiAl & NiGa & NiIn & $\mathrm{CuAl}$ & CuGa & CuIn & $\mathrm{NiCu}$ & $\mathrm{CoCu}$ & AlGa & AlIn & GaIn & HEA \\
\hline $\begin{array}{l}\Delta H_{\text {mix }} \\
\mathrm{kJ} / \mathrm{mol}\end{array}$ & -19 & -11 & 7 & -22 & 1 & 2 & -1 & -15 & 10 & 4 & 6 & 1 & 7 & 3 & $\begin{array}{l}3-2.2 \\
4-8.8\end{array}$ \\
\hline
\end{tabular}

In the case of equiatomic TiZrHfCoNiCu shown in Figure 1a, the weak exothermic peak around $1200 \mathrm{~K}$ corresponds to the precipitation of the $(\mathrm{TiZrHf})_{2}(\mathrm{CoNiCu})$ phase, which takes place in the interdendritic region. The volume fraction of these precipitates is rather small. Still, they appear in interdendritic regions despite the high values for the enthalpy of mixing, $\Delta H_{\text {mix }}=-29.9 \mathrm{~kJ} / \mathrm{mol}$, and the mixing entropy, $\Delta S_{\text {mix }}=14.897 \mathrm{Jmol}^{-1} \mathrm{~K}^{-1}$ (Table 2).

The non-stoichiometric $\left(\mathrm{Co}_{22.33} \mathrm{Ni}_{22.33} \mathrm{Cu}_{22.33}\right)\left(\mathrm{Al}_{11} \mathrm{Ga}_{11} \mathrm{In}_{11}\right)$ has a rather low enthalpy of mixing value, $\Delta H_{\text {mix }}=-2.2 \mathrm{~kJ} / \mathrm{mol}$, while the entropy of mixing is considerably high, $\Delta S_{\text {mix }}=14.407 \mathrm{Jmol}^{-1} \mathrm{~K}^{-1}$ (Table 2). Therefore, this multicomponent intermetallic compound crystallizes supposedly into a dendritic microstructure similar to the one shown in Figure 1a and remains single phase upon cooling down to $1000 \mathrm{~K}$ temperature where it decomposes into two phases (Figure 1b), which are different from the high temperature dendritic one. Cooling by $300 \mathrm{~K}$, to $1000 \mathrm{~K}$, was enough to diminish the entropy contribution to the point where the single phase lost its stability and decomposed. The final microstructure in this case is then a two phase mixture. It seems like the dendrites being depleted in $\mathrm{Cu}$ and In might even release some of them into the interdendritic regions, which were already enriched by these. This then grew into separate phases because the interdendritic regions in their turn 
are depleted in $\mathrm{Co}, \mathrm{Ni}, \mathrm{Al}$, and $\mathrm{Ga}$ and their additional diffusion takes place upon precipitation. As a result, two exothermal peaks can be observed corresponding to the formation of two new phases (Figure $1 \mathrm{~b})$. The black appearing grains of the $\left(\mathrm{Co}_{31.7} \mathrm{Ni}_{26.8} \mathrm{Cu}_{8.5}\right)_{67}\left(\mathrm{Al}_{22.1} \mathrm{Ga}_{10.3} \mathrm{In}_{0.6}\right)_{33}$ phase $(60 \%$ of the volume fraction) are indeed depleted in $\mathrm{Cu}$ and $\mathrm{In}$ and are surrounded by a phase with the composition $\left(\mathrm{Co}_{6.3} \mathrm{Ni}_{13.5} \mathrm{Cu}_{48.9}\right)_{68.7}\left(\mathrm{Al}_{1.5} \mathrm{Ga}_{4.5} \mathrm{In}_{25.3}\right)_{31.3}$, which is depleted in $\mathrm{Co}, \mathrm{Ni}, \mathrm{Al}$, and $\mathrm{Ga}$.

The $\mathrm{Ti}_{16.67} \mathrm{Zr}_{16.67} \mathrm{Hf}_{16.67} \mathrm{Co}_{10} \mathrm{Ni}_{25} \mathrm{Cu}_{15}$ compound also underwent decomposition upon cooling down by about $100 \mathrm{~K}$ below crystallization (Figure 2a). In this case, the enthalpy of mixing is even higher $\left(\Delta H_{\text {mix }}=-31.9 \mathrm{~kJ} / \mathrm{mol}\right.$, Table 2$)$, while the entropy of mixing is only slightly lower $\Delta S_{\text {mix }}$ $=14.61 \mathrm{Jmol}^{-1} \mathrm{~K}^{-1}$ (Table 2) as compared to the equiatomic composition. Two peaks indicate the formation of $\left(\mathrm{Ti}_{32} \mathrm{Zr}_{21.5} \mathrm{Hf}_{8.5}\right)_{62}\left(\mathrm{Co}_{4} \mathrm{Ni}_{17} \mathrm{Cu}_{17}\right)_{38}$, which is similar to (TiZrHf) $)_{2}(\mathrm{CoNiCu})$ case observed in microstructures of the equiatomic compound, and to the formation of $\left(\mathrm{Ti}_{21} \mathrm{Zr}_{20} \mathrm{Hf}_{9}\right)_{50}\left(\mathrm{Co}_{5} \mathrm{Ni}_{21} \mathrm{Cu}_{24}\right)_{50}$ phase (Figure 4). To explain this precipitation process from a seemingly stable (at least according to the high values of enthalpy and entropy of mixing) high temperature phase and formation of martensite crystals within dendrites upon further cooling (cf. Figures 3a and 4), one needs to have a closer look at the values in Table 2. The enthalpy of mixing and the entropy of mixing to a certain extent represent an average measure of the interatomic interaction in the multicomponent intermetallic compound under consideration. In fact, it appears that the interatomic interaction in the highly distorted lattice undergoes a continuous changes upon cooling and represents a key to understanding the competing phase transformations (diffusion and diffusionless). A detailed analysis of these interactions is under way. In the present study, some additional information is extracted using parameters that are average in nature to characterize the collective behavior in the multicomponent alloys. The results for the as-cast $\mathrm{Ti}_{16.67} \mathrm{Zr}_{16.67} \mathrm{Hf}_{16.67} \mathrm{Co}_{10} \mathrm{Ni}_{25} \mathrm{Cu}_{15}$ are shown in Figure 6.

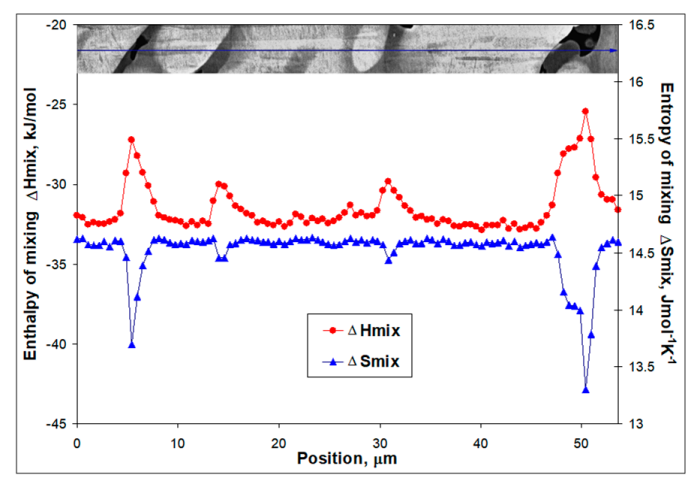

(a)

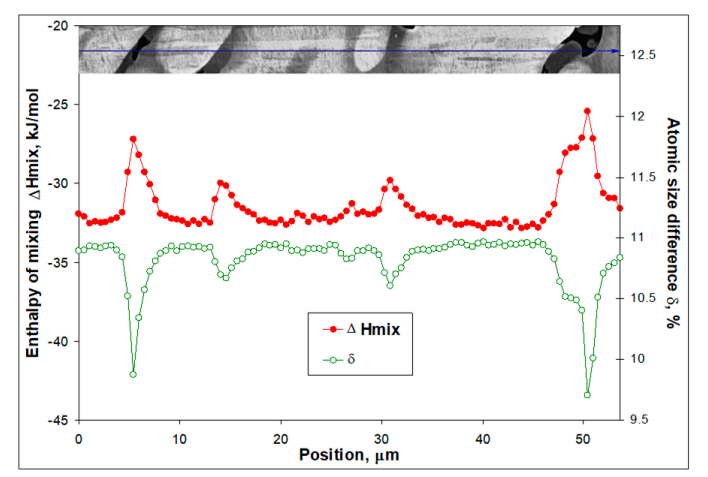

(b)

Figure 6. Changes along the EDX line scan shown in Figure 4 within the as-cast $\mathrm{Ti}_{16.67} \mathrm{Zr}_{16.67} \mathrm{Hf}_{16.67} \mathrm{Co}_{10} \mathrm{Ni}_{25} \mathrm{Cu}_{15}$ for: (a) enthalpy (closed circles) and entropy (closed triangles) of mixing calculated as described for Table 2 according to [22,23]; (b) enthalpy of mixing (closed circles) and atomic size difference (open circles) calculated according to [23].

The dependencies in Figure 6 show a clear anti correlation. The correlation coefficient for the enthalpy and entropy of mixing pair is -0.87 (Figure 6a), while the enthalpy of mixing and the atomic size difference show an even-better anti correlation (correlation coefficient is -0.95 ; Figure $6 \mathrm{~b}$ ). First of all, this means that lattice distortions are followed more accurately by the atomic size difference and the enthalpy of mixing no matter how average these values are. The entropy of mixing calculated here according to the Boltzmann equation reflects chemical changes only. On the other hand, it can be seen that the dendrite region shows the highest entropy of mixing and atomic size difference. This is the region where the martensite crystals actually appeared. The interdendritic regions are unreachable for martensite although there is no clear boundary between the interdendritic regions and the dendrites. The stabilization of these regions with respect to the martensitic transformation is accompanied by lower negative values of the enthalpy of mixing, lower entropy of mixing and change in atomic 
size difference. In other words, the martensite crystals are not able to penetrate the less distorted interdendritic regions that are also less stable. Here the loss in stability can be related to diffusional phase transformations, which have been confirmed by the precipitation of $(\mathrm{TiZrHf})_{2}(\mathrm{CoNiCu})$ in these regions as detected by DTA (Figures $1 \mathrm{a}$ and $2 \mathrm{a}$ ) and observed by SEM (Figures 3a, 4 and 6).

Next it is considered how the same line of thinking can be applied to the case of the as-cast $\mathrm{Co}_{31.22} \mathrm{Ni}_{29.26} \mathrm{Cu}_{11.95} \mathrm{Al}_{16.64} \mathrm{Ga}_{10.39} \mathrm{In}_{0.55}$ intermetallic compound. The description given previously for the results in Figure 5 will be expanded here using the data given in Figure 5a. To analyze the concentration profiles, they were first smoothened as described in Section 2. Smoothened concentration variations for $\mathrm{Co}, \mathrm{Ni}, \mathrm{Cu}, \mathrm{Al}$, and $\mathrm{Ga}$ along a $38 \mu \mathrm{m}$ scan are plotted in Figure 7 . In addition, entropy of mixing and atomic size difference are included in Figure 7 as well. For the sake of clarity, the enthalpy of mixing dependence and the In concentration profile are not shown. The enthalpy of mixing correlates extremely well with the $\mathrm{Cu}$ concentration profile (correlation coefficient is 0.99 ) as well as with the entropy of mixing (correlation coefficient is 0.99 ).

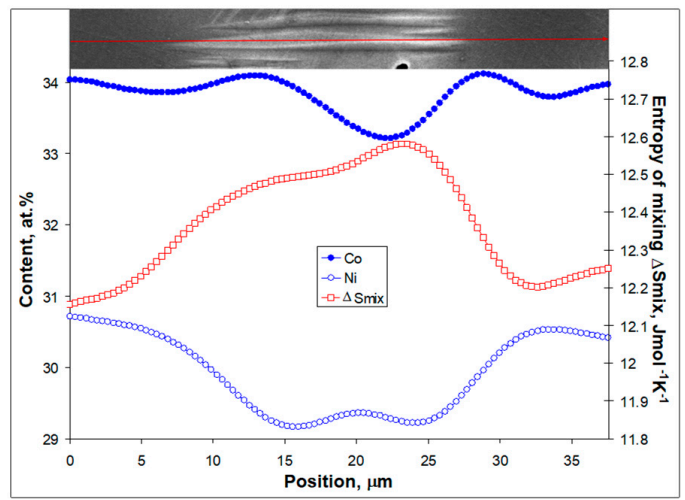

(a)

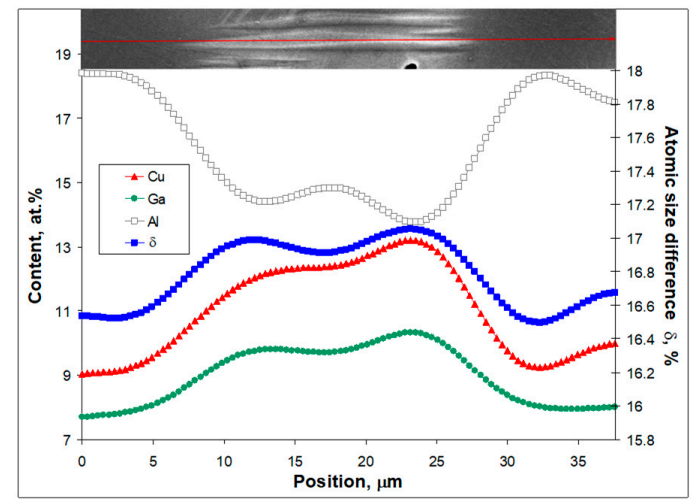

(b)

Figure 7. Variation of key parameters along the EDX line scan shown in Figure 5a within the as-cast $\mathrm{Co}_{31.22} \mathrm{Ni}_{29.26} \mathrm{Cu}_{11.95} \mathrm{Al}_{16.64} \mathrm{Ga}_{10.39} \mathrm{In}_{0.55}$ : (a) smoothened concentration profiles of Co (closed circles), $\mathrm{Ni}$ (open circles) and entropy of mixing calculated as described for Table 2 according to [23] (open boxes); (b) smoothened $\mathrm{Cu}$ (closed triangles), $\mathrm{Ga}$ (closed circles), $\mathrm{Al}$ (open boxes) concentration profiles, and atomic size difference (closed boxes) calculated according to [23].

Figure 7 shows all the variation in the key parameters with the as-cast microstructure and near perfect correlations of the Ga concentration profile with atomic size difference (correlation coefficient is 0.97) and $\mathrm{Ni}$ with $\mathrm{Al}$ (correlation coefficient is 0.95 ). In other words, dendrite regions (dark appearing ones on the right and left hand sides of the interdendritic region shown in Figures 5a and 7) are enriched in $\mathrm{CoAl}$ and $\mathrm{NiAl}$ as those started to crystallize from the most refractory compounds (see Table 1). As the scan is followed into the interdendritic region, a depletion in $\mathrm{Ni}$ (Figure 7a) and $\mathrm{Al}$ (Figure 7b) becomes apparent. It should be noted that martensite crystal displays similar trends at this position. At the same time, lower melting point constituents like $\mathrm{Cu}, \mathrm{Ga}$, and In are enriched in interdendritic regions instead of $\mathrm{Ni}, \mathrm{Al}$, and $\mathrm{Co}$. Still, the Co concentration profile does not correlate well with any of the other dependencies seen in Figure 7. It goes through a maximum, which is followed by a minimum. This concentration changes only by about one at $\%$, which can be the reason why martensite crystal did not stop when coming through the Co concentration wave shown in Figure 7a. Other elements (except In) undergo stronger changes coming from the dendrite into the interdendritic region.

Comparing this case with TiZrHfCoNiCu (Figure 6), it should be noted that martensite crystals appear similarly in the regions that are more distorted (atomic size difference increases-Figure $7 \mathrm{~b}$ ) and the enthalpy of mixing has a lower negative value. However, one more important difference has to be noticed. The region where the martensitic crystals appears is not a dendrite but an interdendritic one. Moreover, the entropy of mixing (Figure 7a) undergoes an increase in this region as well as the atomic size difference (Figure $7 \mathrm{~b}$ ). Once again, similarly to $\mathrm{TiZrHfCoNiCu}$, the martensite crystals 
propagate through highly distorted regions but are not able to penetrate less distorted regions of the CoNiCuAlGaIn intermetallic compound. The only difference is that in the former case martensite forms in dendrites, while in the latter-in interdendritic regions. These findings are in agreement with the results reported in Reference [16], where it was concluded that the distorted crystal structure of TiZrHfCoNiCu intermetallic compounds is even better prepared for martensitic transformation than binary TiNi or $\mathrm{ZrCu}$.

\section{Summary and Outlook}

The high entropy shape memory alloys (HESMA) studied in the present paper feature a martensitic transformation and shape memory behavior in the as-cast state [14-17]. The present study has shown that this state is characterized by strong dendritic liquation that develops into similar multi-phase microstructures. Yet two different crystallization scenarios evolve that result in the formation of martensite in dendrites or interdendritic regions. Control of the crystallization parameters might allow one to refine the final microstructures to obtain cast and ready to use HESMA without subsequent solutionizing. This might become extremely useful, especially in the case of 3D printing using HESMA. It should be noted that following the first HESMA breakthrough described in References [14-17], in these publications where solutionized composition $\mathrm{Ti}_{16.67} \mathrm{Zr}_{16.67} \mathrm{Hf}_{16.67} \mathrm{Co}_{10} \mathrm{Ni}_{25} \mathrm{Cu}_{15}$ was studied $[15,16]$. Yet, quite significant remnants of $\mathrm{Ti}_{2} \mathrm{Ni}$ like precipitates were observed in the microstructure after solution treatment $[24,25]$. The present findings clearly show the inevitability of such precipitations as interdendritic regions are provide template-like sites for those precipitates. Obviously, such precipitations will affect the functional properties as it was shown already for the TiNi binary system. The authors of References [24,25] have shown that starting at $200 \mathrm{MPa}$ applied external stress, the shape memory effects start to degrade upon fatigue of solutionized $\mathrm{Ti}_{16.67} \mathrm{Zr}_{16.67} \mathrm{Hf}_{16.67} \mathrm{Co}_{10} \mathrm{Ni}_{25} \mathrm{Cu}_{15}$. Amongst other possible reasons for such behavior might be the presence of precipitates. It is clear that simple solution treatments cannot fully avoid their formation. Realization of a homogeneous microstructure suitable for fully reversible martensitic transformation associated with a stable-shape memory behavior will be challenging. In fact, a single-phase material might not be the best solution in this case.

Author Contributions: Conceptualization, T.A.K., H.J.M., and G.S.F.; Data curation, G.S.F.; Formal analysis, Y.N.K.; Investigation, T.A.K., G.G., V.V.O., and G.S.F.; Methodology, G.G.; Validation, Y.N.K.; Writing original draft, G.S.F.; Writing review \& editing, G.G. and H.J.M.

Funding: This research was funded by the Deutsche Forschungsgemeinschaft (DFG) (project number 388671975, contract No. MA1175/79-1 is gratefully acknowledged). Financial support by the fundamental Project of the National Academy of Sciences of Ukraine (Project number 0118U001038) is also gratefully acknowledged.

Conflicts of Interest: The authors declare no conflict of interest.

\section{References}

1. Yeh, J.W.; Chen, S.K.; Lin, S.G.; Gan, J.Y.; Chin, T.S.; Shun, T.T.; Tsau, C.H.; Chang, S.Y. Nanostructured high entropy alloys with multiple principal elements: Novel alloy design concepts and outcomes. Adv. Eng. Mater. 2004, 6, 299-303. [CrossRef]

2. Zhang, Y.; Zuo, T.T.; Nang, Z.; Cao, M.C.; Dahmen, K.A.; Liaw, P.K.; Lu, Z.P. Microstructures and properties of high entropy alloys. Prog. Mater. Sci. 2014, 61, 1-93. [CrossRef]

3. Murty, B.S.; Yeh, J.-W.; Ranganathan, S. High Entropy Alloys; Elsevier Science \& Technology: Amsterdam, The Netherlands; Butterworth-Heinemann Ltd.: Oxford, UK, 2014; p. 204.

4. Cantor, B. Multicomponent and High Entropy Alloys. Entropy 2014, 16, 4749-4768. [CrossRef]

5. Ye, Y.F.; Wang, Q.; Lu, J.; Liu, C.T.; Yang, Y. High-entropy alloy: Challenges and prospects. Mater. Today 2016, 19, 349-362. [CrossRef]

6. Gorban', V.F.; Krapivka, N.A.; Firstov, S.A. High-entropy alloys: Interrelations between electron concentration, phase composition, lattice parameter, and properties. Phys. Met. Metallogr. 2017, 118, 970-981. [CrossRef] 
7. Firstov, G.S.; Van Humbeeck, J.; Koval, Y.N. High-temperature shape memory alloys. Some recent developments. Mater. Sci. Eng. A 2004, 378, 2-10. [CrossRef]

8. Firstov, G.S.; Van Humbeeck, J.; Koval, Y.N. High Temperature Shape Memory Alloys Problems and Prospects. J. Intel. Mater. Sys. Struct. 2006, 17, 1041-1047. [CrossRef]

9. Ma, J.; Karaman, I.; Noebe, R.D. High temperature shape memory alloys. Int. Mater. Rev. 2010, 55, $257-315$. [CrossRef]

10. Niendorf, T.; Krooß, P.; Batyrsina, E.; Paulsen, A.; Motemani, Y.; Ludwig, A.; Buenconsejo, P.; Frenzel, J.; Eggeler, G.; Maier, H.J. Functional and structural fatigue of titanium tantalum high temperature shape memory alloys. Mater. Sci. Eng. A 2015, 620, 359-366. [CrossRef]

11. Firstov, G.; Koval, Y.; Van Humbeeck, J.; Timoshevskii, A.; Kosorukova, T.; Verhovlyuk, P. Some physical principles of high temperature shape memory alloys design. In Shape Memory Alloys: Properties, Technologies, Opportunities; Resnina, N., Rubanik, V., Eds.; Trans Tech Publications Inc.: Zurich, Switzerland, 2015; pp. 207-232. [CrossRef]

12. Senkov, O.N.; Scott, J.M.; Senkova, S.V.; Miracle, D.B.; Woodward, C.F. Microstructure and room temperature properties of a high-entropy TaNbHfZrTi alloy. J. Alloys Compd. 2011, 509, 6043-6048. [CrossRef]

13. Firstov, S.A.; Rogul', T.G.; Krapivka, N.A.; Ponomarev, S.S.; Tkach, V.N.; Kovylyaev, V.V.; Gorban', V.F.; Karpets, M.V. Solid-solution hardening of a high-Entropy AlTiVCrNbMo alloy. Russ. Metall. 2014, 2014, 285-292. [CrossRef]

14. Firstov, G.S.; Kosorukova, T.A.; Koval, Y.N.; Odnosum, V.V. High entropy shape memory alloys. Mater. Today Proc. 2015, 2S, S499-S504. [CrossRef]

15. Firstov, G.S.; Kosorukova, T.A.; Koval, Y.N.; Verhovlyuk, P.A. Directions for High-Temperature Shape Memory Alloys' Improvement: Straight Way to High-Entropy Materials? Shape Mem. Superelast. 2015, 1, 400-407. [CrossRef]

16. Firstov, G.; Timoshevskii, A.; Kosorukova, T.; Koval, Y.; Matviychuk, Y.; Verhovlyuk, P. Electronic and crystal structure of the high entropy TiZrHfCoNiCu intermetallics undergoing martensitic transformation. MATEC Web Conf. 2015, 33, 06006. [CrossRef]

17. Gerstein, G.; Firstov, G.S.; Kosorukova, T.A.; Koval, Y.N.; Maier, H.J. Development of B2 Shape Memory Intermetallics Beyond NiAl, CoNiAl and CoNiGa. Shap. Mem. Superelast. 2018, 4, 360-368. [CrossRef]

18. Lee, J.I.; Tsuchiya, K.; Tasaki, W.; Oh, H.S.; Sawaguchi, T.; Murakami, H.; Hiroto, T.; Matsushita, Y.; Park, E.S. A strategy of designing high-entropy alloys with high-temperature shape memory effect. Sci. Rep. 2019, 9, 13140. [CrossRef]

19. Couzinié, J.P.; Dirras, G.; Perrière, L.; Chauveau, T.; Leroy, E.; Champion, Y.; Guillot, I. Microstructure of a near-equimolar refractory high-entropy alloy. Mater. Lett. 2014, 126, 285-287. [CrossRef]

20. Firstov, S.A.; Gorban, V.F.; Krapivka, N.A.; Pechkovsky, E.P.; Karpets, M.V.; Ponomarev, S.S.; Kovyljaev, V.A. Elemental distribution in as-cast multicomponent high-entropy single phase alloys with bcc crystalline lattice. Compos. Nanostruct. 2012, 3, 48-64.

21. Inorganic Material Database (AtomWork). Available online: https://crystdb.nims.go.jp/index_en.html (accessed on 29 October 2019).

22. Takeuchi, A.; Inoue, A. Classification of Bulk Metallic Glasses by Atomic Size Difference, Heat of Mixing and Period of Constituent Elements and Its Application to Characterization of the Main Alloying Element. Mater. Trans. 2005, 46, 2817-2829. [CrossRef]

23. Zhang, Y.; Zhou, Y.J.; Lin, J.P.; Chen, G.L.; Liaw, P.K. Solid-Solution Phase Formation Rules for Multi-component Alloys. Adv. Eng. Mater. 2008, 10, 534-538. [CrossRef]

24. Chen, C.-H.; Chen, Y.-J. Shape memory characteristics of (TiZrHf) ${ }_{50} \mathrm{Ni}_{25} \mathrm{Co}_{10} \mathrm{Cu}_{15}$ high entropy shape memory alloy. Scr. Mater. 2019, 162, 185-189. [CrossRef]

25. Lee, H.-C.; Chen, Y.-J.; Chen, C.-H. Effect of Solution Treatment on the Shape Memory Functions of (TiZrHf) ${ }_{50} \mathrm{Ni}_{25} \mathrm{Co}_{10} \mathrm{Cu}_{15}$ High Entropy Shape Memory Alloy. Entropy 2019, 21, 1027. [CrossRef]

(C) 2019 by the authors. Licensee MDPI, Basel, Switzerland. This article is an open access article distributed under the terms and conditions of the Creative Commons Attribution (CC BY) license (http://creativecommons.org/licenses/by/4.0/). 